\title{
Argilas adsorventes aplicadas à clarificação de óleos vegetais
}

\section{(Adsorbent clays applied in vegetable oil clarification)}

\author{
J. S. Patricio' ${ }^{1}$ D. Hotza ${ }^{1}$, A. De Noni Júnior ${ }^{2}$ \\ ${ }^{1}$ Programa de Pós-Graduação em Ciência e Engenharia de Materiais, Universidade Federal de Santa Catarina \\ Florianópolis, SC 88040-900 \\ ${ }^{2}$ Programa de Pós-Graduação em Ciência e Engenharia de Materiais, Universidade do Extremo Sul de Santa \\ Catarina Criciúma, SC 88806-000 \\ dhotza@gmail.com
}

\begin{abstract}
Resumo
Argilas com propriedades adsorventes são utilizadas em uma das fases do refino para a produção de óleos vegetais para consumo humano. Essas argilas são geralmente definidas como argilas descolorantes, e a sua principal função é eliminar a clorofila e carotenoides do óleo vegetal. A maior parte das argilas comerciais descorantes é obtida a partir de esmectitas tratadas com ácidos inorgânicos fortes. O tratamento com ácido promove a criação de sítios ácidos, o aumento de área de superfície específica, volume e tamanho de poro, a dissolução de impurezas e outras modificações que contribuem para melhorar as propriedades de adsorção de tais materiais.
\end{abstract}

Palavras-chave: argilas descorantes, ativação ácida, adsorção.

Abstract

Clays with adsorbent properties are used in one of the refining stages for the production of vegetable oil for human consumption. Those clays are often defined as discoloring clays, and their main function is to remove chlorophyll and carotenoid of the vegetable oil. Most of the commercial discoloring clays are obtained from smectites treated with strong inorganic acids. The acid treatment promotes the creation of acidic sites, increase of specific surface area, volume and pore size, dissolution of impurities and other changes that contribute to enhance the adsorbent properties of those materials.

Keywords: discoloring clays, acid activation, adsorption.

\section{INTRODUÇÃO}

A utilização de argilas para remoção de pigmentos em óleos vegetais não é um procedimento novo. As terras Fuller (Fuller's earth) são utilizadas há muito tempo na clarificação ou descoramento de óleos vegetais e gorduras animais. Esses materiais não necessitam da aplicação de nenhum tratamento físico ou químico, pois possuem uma capacidade descorante natural [1-3]. As propriedades de descoramento de óleos vegetais, apresentadas pelas terras Fuller, motivaram estudos que revelaram que alguns tipos de argila apresentavam propriedades de adsorção de pigmento quando submetidas a algum tipo de tratamento (químico ou físico).

Diversos tipos de tratamento em argilas e outros minerais podem ser aplicados com o objetivo de incrementar as propriedades de adsorção de pigmentos presentes em óleos vegetais.

Quase a totalidade das argilas comerciais disponíveis para a clarificação de óleo pertence ao grupo das esmectitas, mais especificamente das montmorilonitas cálcicas, ativadas com ácidos inorgânicos fortes (ácido sulfúrico ou ácido clorídrico) [4]. A remoção dos pigmentos de óleos vegetais é indispensável para que o óleo possa ser comercializado em embalagens transparentes do tipo PET. Se não houver a retirada do pigmento clorofila, um composto fotossensível, a degradação do óleo ocorrerá em um curto período de tempo.

Este artigo apresenta uma revisão bibliográfica sobre os aspectos relacionados a argilas com estrutura e superfície modificadas, aplicadas à clarificação de óleos vegetais.

\section{ÓLEOS VEGETAIS}

Os óleos vegetais são produtos naturais constituídos por uma mistura de ésteres derivados do glicerol (triacilgliceróis ou triglicerídios), cujos ácidos graxos contêm cadeias de 8 a 24 átomos de carbono com diferentes graus de insaturação. Conforme a espécie de oleaginosa, variações na composição química do óleo vegetal são expressas por variações na relação molar entre os diferentes ácidos graxos presentes na estrutura [5]. Os principais pigmentos presentes nos óleos vegetais são as clorofilas e os carotenoides.

\section{Clorofilas}

As clorofilas são os pigmentos naturais mais abundantes 
presentes nas plantas e ocorrem nos cloroplastos das folhas e em outros tecidos vegetais. Estudos em uma grande variedade de plantas caracterizaram que os pigmentos clorofilianos são os mesmos. As diferenças aparentes na cor do vegetal são devidas à presença e distribuição variável de outros pigmentos associados, como os carotenoides, os quais sempre acompanham as clorofilas [6].

As clorofilas são moléculas formadas por complexos derivados da porfirina, tendo como átomo central o Mg (Fig. 1). Esse composto é uma estrutura macrocíclica assimétrica totalmente insaturada constituída por quatro anéis de pirrol (Fig. 2) [5].

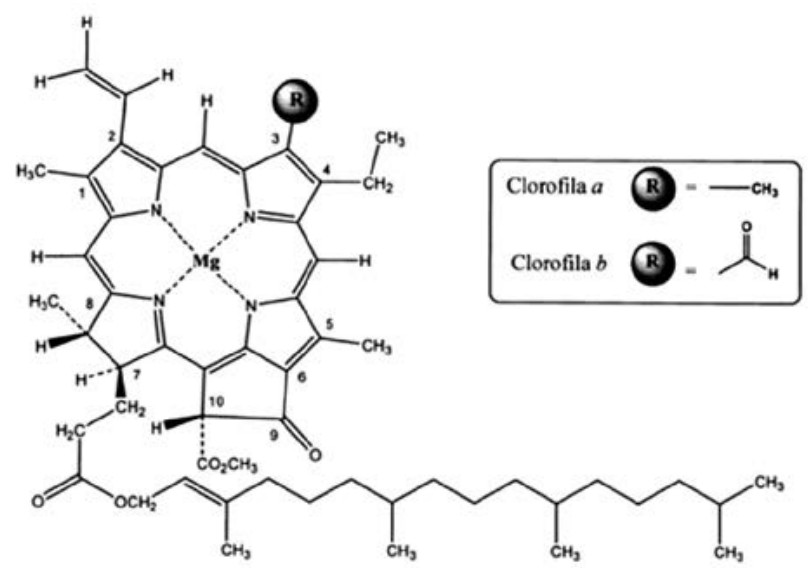

Figura 1: Estrutura química da molécula de clorofila [5].

[Figure 1: Chemical structure of the chlorophyll molecule [5].]

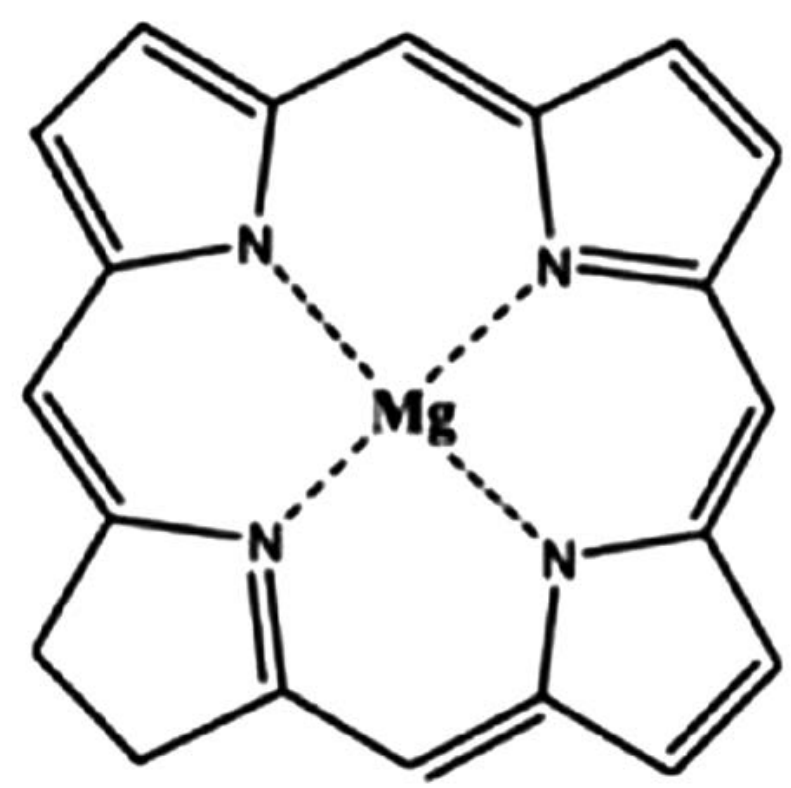

Figura 2: Estrutura química dos anéis de pirrol [5].

[Figure 2: Chemical structure of pyrrole rings [5].]

As moléculas de clorofila são fotossensíveis, provocando reações de oxidação nos óleos vegetais quando os mesmos são expostos à luz. Estas reações degradam as características do óleo tornando-o impróprio para o consumo. Com o advento das embalagens transparentes (PET) intensificaramse os esforços para remover estes compostos.

\section{Carotenoides}

Os carotenoides são, como as clorofilas, pigmentos presentes em óleos vegetais. Encontram-se representados pelos carotenos (hidrocarbonetos) e carotenóis (alcoóis), podendo ser amarelos, vermelhos ou púrpuros. $\mathrm{O}$ mais importante, com mais de 70 variedades conhecidas [7, 8] é o betacaroteno, precursor da vitamina A nos animais, um composto isoprenoide vermelho alaranjado com absorção relacionada com o sistema extensivo de duplas ligações conjugadas, ocorrendo próximo ao ultravioleta e ao azulverde do espectro, portanto na faixa de 420-475 nm [9].

Estáveis em álcalis e instáveis aos ácidos, ao calor e à oxidação, os carotenoides são insolúveis em água e solúveis em gorduras e facilmente removíveis na hidrogenação, na dependência do ataque do sistema de duplas conjugadas (Fig. 3) [5]. Pelo fato de extinguirem o oxigênio, os carotenos são os únicos pigmentos naturais não fotooxidáveis [9].

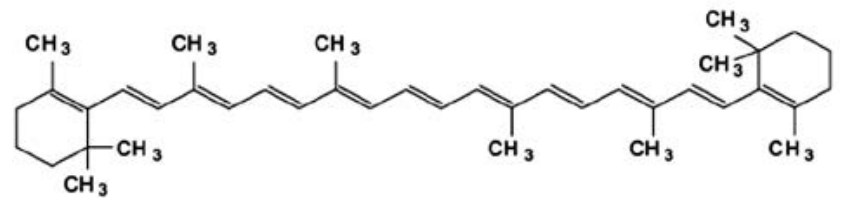

Figura 3: Estrutura química da molécula de betacaroteno [9]. [Figure 3: Chemical structure of the carotene molecule [9].]

Enquanto a necessidade de remoção da clorofila envolve aspectos relacionados à qualidade final do óleo (propriedades e características organolépticas), a remoção de betacaroteno é um aspecto mais comercial do que técnico. Remove-se o betacaroteno com o objetivo de tornar o óleo claro, sem a cor vermelho-alaranjada proporcionada pela presença deste composto.

\section{ARGILAS DESCORANTES}

Os termos "argila descorante", "terra descorante", "argila clarificante" ou "argila adsorvente" são utilizados nas indústrias de óleos para designar argilas que, no estado natural ou após ativação química ou térmica, apresentam a propriedade de adsorver as matérias corantes dissolvidas de óleos minerais, vegetais e animais [5]. Outros termos como "argila ativada", "terra ativada" e "terra de branqueamento" também são aplicados aos materiais adsorventes utilizados no processo de refino de óleos vegetais.

A argila é um material natural, terroso, de granulação fina, que geralmente adquire, quando umedecido com água, certa plasticidade. Quimicamente, as argilas são formadas por silicatos hidratados de alumínio, ferro e magnésio [1-3]. Designa-se ainda de argila a um grupo de partículas do solo cujas dimensões se encontram entre uma faixa especificada de valores (partículas com dimensões menores que 0,002 $\mathrm{mm}$ ) [10]. Sabe-se que as argilas são constituídas por um ou mais argilominerais, além de impurezas como quartzo, carbonatos e feldspatos [1-3].

Segundo Mackenzie [11], define-se argilominerais como 
minerais constituintes das argilas, geralmente cristalinos; correspondentes a silicatos de alumínio hidratados, contendo certos tipos de elementos como magnésio, ferro, cálcio, sódio, potássio, lítio, entre outros. Entre os argilominerais mais comuns estão a caulinita, a esmectita e a ilita. Cada argilomineral possui características próprias que definem sua utilização na indústria.

Os argilominerais do grupo das esmectitas têm aplicação em diversos processos industriais, como em tintas e vernizes, cosméticos, fluídos tixotrópicos utilizados na perfuração de poços, produtos para adsorção de metais pesados, entre outros. Para aplicação em processos de clarificação de óleos vegetais, passam por um processo de ativação com ácidos minerais, usualmente ácido sulfúrico.

Tecnologicamente, as argilas esmectíticas são geralmente denominadas bentonitas. Geologicamente, bentonita é uma rocha constituída essencialmente por um argilomineral esmectítico (montmorilonita), formado pela devitrificação e subsequente alteração química de um material vítreo, de origem ígnea, usualmente um tufo ou cinza vulcânica, ácida de preferência [1-3].

O termo bentonita foi derivado da localização do primeiro depósito comercial de uma argila plástica, em Fort Benton, Wyoming, nos Estados Unidos [12]. Essa argila apresenta a propriedade de aumentar várias vezes o seu volume inicial na presença de umidade.

Osargilominerais do grupodasesmectitas (montmorilonita, beidelita, nontronita, entre outros) são constituídos por duas folhas tetraédricas de sílica, com uma folha central octaédrica de alumínio, unidas entre si por oxigênios comuns às folhas (estrutura do tipo 2:1) conforme Fig. 4.

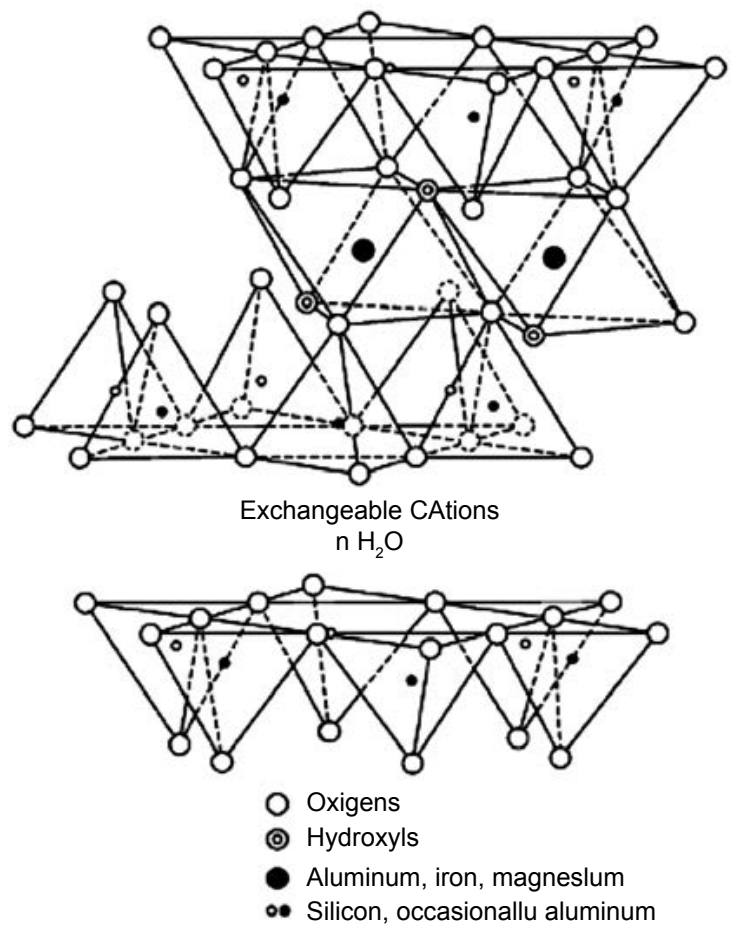

Figura 4: Estrutura cristalina da esmectita [13].

[Figure 4: Crystal structure of smectite [13].]
Durante a formação dos cristais de esmectita, podem ocorrer substituições isomórficas nas folhas tetraédricas de $\mathrm{Si}^{4+}$ por $\mathrm{Al}^{3+}$ e nas folhas octaédricas de $\mathrm{Al}^{3+}$ por $\mathrm{Mg}^{2+}$ ou $\mathrm{Fe}^{2+}$, de forma isolada ou em combinação. $\mathrm{O}$ número de cátions que ocupam as posições dentro da folha octaédrica determina se um mineral de argila é di ou trioctaedral. Se $\mathrm{Al}^{3+}$ está presente na folha octaédrica, então o mineral é dioctaedral. Se o $\mathrm{Mg}^{2+}$ está presente temos um mineral trioctaedral. Dependendo da posição e da natureza do átomo isomorficamente substituído tem-se a formação de diferentes argilominerais no grupo das esmectitas, conforme a Fig. 5.

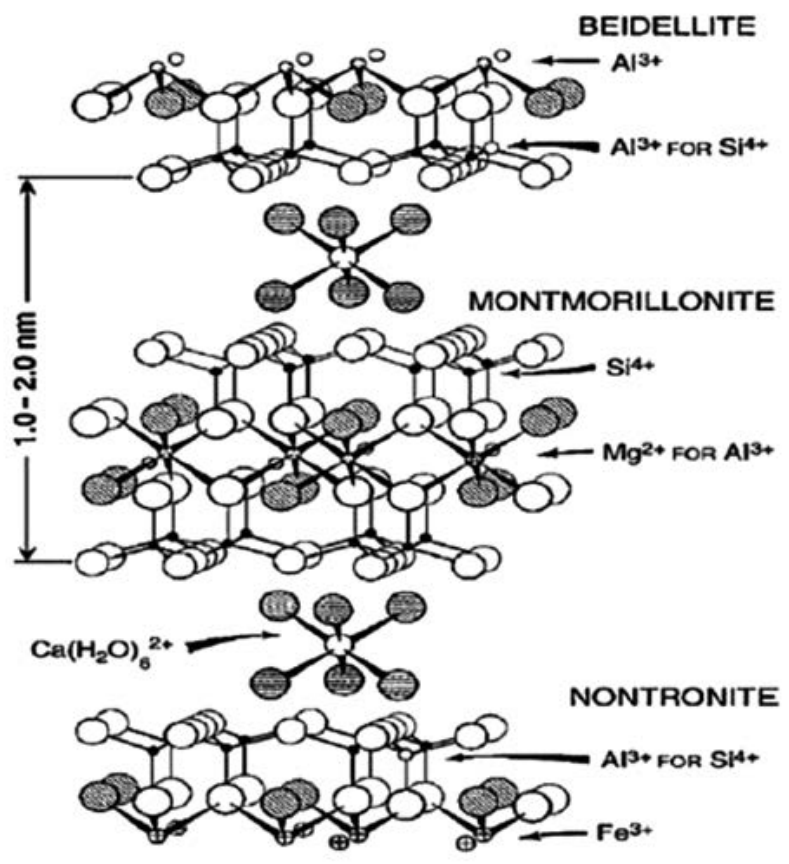

Figura 5: Substituições isomórficas nas esmectitas [24]. [Figure 5: Isomorphic substitutions in smectites [24].]

As substituições isomórficas, juntamente com as ligações partidas nas arestas dos cristais, geram deficiências de cargas positivas nos mesmos que são compensadas por cátions trocáveis. Essa característica está associada à capacidade de troca catiônica (CTC), expressa em meq/100 g. O efeito da secagem sobre a CTC em bentonitas e argilas contendo uma mistura de ilita e esmectita foi estudado [14]. Foi observado que nas amostras houve diminuição da CTC em função do aumento de temperatura e ciclo de secagem.

Outra característica muito importante dos argilominerais do grupo das esmectitas é a elevada área superficial específica, quando comparada a argilominerais de outros grupos.

Esmectitas que incham e que não incham são idênticas em composição mineralógica, diferindo nos cátions trocáveis, que são, no tipo que não incha, cálcio e magnésio. Se o cálcio e o magnésio forem trocados totalmente pelo sódio, a propriedade de inchamento e de dispersão espontânea em água é adquirida se o magnésio e o ferro em substituição isomórfica estiverem em baixa proporção [1-3].

Argilas esmectíticas brasileiras foram estudadas e foram 
encontrados valores de área superficial específica de $\sim 88$ $\mathrm{m}^{2} / \mathrm{g}$, CTC entre 32 e $88 \mathrm{meq} / 100 \mathrm{~g}$ e inchamento livre de $4 \mathrm{a} 15 \mathrm{~mL} / \mathrm{g}$ [15]. Estudos específicos sobre bentonitas brasileiras aplicadas à clarificação de óleos vegetais não foram encontrados na literatura.

\section{ATIVAÇÃO ÁCIDA DE ESMECTITAS}

Montmorilonitas ativadas por ácido são utilizadas no branqueamento de óleos e gorduras comestíveis; óleos, gorduras e ceras industriais; sabões e sabonetes; componentes orgânicos de vernizes e tintas; na reciclagem de óleos lubrificantes usados em motores à explosão e para purificação de óleos isolantes para transformadores e turbinas elétricas [4].

É importante destacar que não somente os argilominerais esmectíticos do tipo montmorilonita podem ser ativados por tratamento com ácidos inorgânicos fortes. As propriedades da glauconita ativada com ácido foram estudadas [16]. Os efeitos do aquecimento e tratamento ácido na distribuição de tamanhos dos poros em uma sepiolita foram estudados [17]. As modificações na estrutura de paligorsquitas e sepiolitas após o tratamento com ácido foram identificados [18]. As características de uma argila ativada comercial foram comparadas com as características de uma argila contendo sepiolita e com poder descorante natura [19]. Uma bauxita ativada antes e depois de sua utilização como adsorvente de óleos isolantes elétricos foi caracterizada [20]. No entanto, quase a totalidade da produção mundial de argilominerais ácido-ativados utiliza montmorilonita.

A ativação ácida pode ser feita em uma montmorilonita mono ou policatiônica, não importando quais sejam os cátions. Contudo, considerando que a montmorilonita cálcica ou policatiônica, sendo $\mathrm{Ca}^{2+} \mathrm{o}$ cátion trocável predominante, é de ocorrência mais frequente e com o menor preço, a ativação ácida (com ácido sulfúrico ou clorídrico) é usualmente feita em bentonitas cálcicas [4]. Não há evidência direta de que montmorilonitas sódicas não possam gerar material adsorvente de pigmentos presentes em óleos vegetais após tratamento com ácidos inorgânicos fortes. Porém, as montmorilonitas sódicas apresentam dificuldades durante o processo de ativação: suspensões de elevada viscosidade e consequentemente necessidade de baixa concentração de sólidos, dificuldade com operação de mistura e transporte da suspensão ácida [21].

O processo de ativação consiste na formação de uma mistura de água, argila e ácido (geralmente ácido sulfúrico) com proporções previamente definidas em um reator. A mistura é mantida sob agitação e aquecimento por um determinado tempo. Terminado o tempo de ativação, a argila passa por uma lavagem com água que tem por objetivo retirar o excesso de ácido. Após a lavagem a argila ativada é seca, triturada e embalada. A ativação de argilas bentoníticas diferentes foi estudada e foi concluído que cada argila bentonítica apresenta condições de processamento distintas para a obtenção do maior poder de clarificação de óleo de palma [22].

\section{Modificações estruturais após ativação ácida}

O tratamento com ácidos serve para três objetivos: dissolver alguma impureza da bentonita (calcita ou gipsita); substituir o cálcio e outros cátions intercalados por cátions hidroxônio $\mathrm{H}_{3} \mathrm{O}^{+}$; dissolver, nas folhas octaédricas das camadas 2:1 (próximo à superfície dos empilhamentos ou em suas bordas), alguns cátions $\mathrm{Mg}^{2+}, \mathrm{Al}^{3+}, \mathrm{Fe}^{3+}$ ou $\mathrm{Fe}^{2+}$. Alterações morfológicas muito importantes acontecem na estrutura cristalina da montmorilonita durante e após a ativação ácida. Os extremos e as arestas das camadas 2:1 lamelares dos cristais desorientam-se, separam-se e ficam como em um leque aberto (são constituídos por folhas flexíveis e moles de ácido silícico); entretanto, o centro do cristal não se altera e mantém a distância interplanar original. Os cátions trocáveis originais são substituídos por $\mathrm{Al}^{3+} \mathrm{e} \mathrm{H}^{+}$hidratados. Os diâmetros dos poros aumentam e o seu volume interno fica mais facilmente acessível a líquidos e gases. Tanto a área específica dos cristais quanto o seu "poder descorante" (bleaching performance) aumentam até atingir valores máximos (que são dependentes da argila original) e, depois, ambos diminuem com o tempo de ataque por ácido [4].

As propriedades estruturais das argilas naturais são modificadas pelos métodos de ativação ácida, produzindo materiais com áreas superficiais maiores, maior acidez e porosidade, além de boa estabilidade térmica. Tais tratamentos causam a troca iônica dos cátions interlamelares $\left(\mathrm{Na}^{+}\right.$ou $\left.\mathrm{Ca}^{2+}\right)$ por $\mathrm{H}^{+}$e fazem com que cátions das lamelas cristalinas, como $\mathrm{Al}^{3+}$ das folhas octaédricas, sejam retirados das suas posições na estrutura cristalina, deixando os grupos tetraédricos $\mathrm{SiO}_{4}$ intactos. Esse processo geralmente aumenta a área superficial de argilas brutas em até cinco vezes, e também a sua acidez, junto com a eliminação de muitas impurezas minerais e a dissolução parcial das lamelas cristalinas [23].

Em geral, o processo de ativação ácida consiste em duas etapas: (1) a substituição de cátions trocáveis por prótons $\left(\mathrm{H}_{3} \mathrm{O}^{+}\right)$e (2) a dissolução de íons de metais da estrutura da argila, removidos da folha octaédrica [24]. De acordo com [25], durante o ataque ácido os cátions trocáveis são substituídos por prótons $\left(\mathrm{H}_{3} \mathrm{O}^{+}\right)$e os cátions da folha octaédrica $\left(\mathrm{Al}^{3+}, \mathrm{Mg}^{2+}, \mathrm{Fe}^{2+}, \mathrm{Fe}^{3+}\right)$ são dissolvidos. Com isso, é gerado um produto amorfo, de alto conteúdo de $\mathrm{SiO}_{2}$, com uma elevada área superficial específica e presença de micro e mesoporos. O poder de branqueamento depende dos parâmetros do processo de ativação (concentração de ácido, temperatura e tempo). A composição da camada octaédrica do argilomineral afeta substancialmente sua estabilidade contra o ataque ácido. Camadas trioctaedrais (compostas por $\mathrm{Mg}^{2+}$ ou $\mathrm{Fe}^{2+}$ ) dissolvem mais rapidamente do que as camadas dioctaedrais (compostas por $\mathrm{Al}^{3+}$ ).

No estudo apresentado por He et al. [26], à medida que se aumentou a concentração de ácido sulfúrico para a ativação de bentonitas, houve um aumento da lixiviação dos cátions

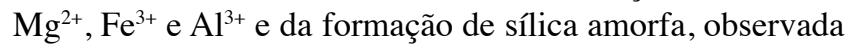
através das análises de FRX e DRX. 
Na Fig. 6, são apresentadas as etapas de ativação e as modificações sofridas pela estrutura da argila ao longo do tempo de ativação. Inicialmente a solução ácida remove os cátions trocáveis ( $\mathrm{Ca}$ e $\mathrm{Mg})$. Com o passar do tempo da reação há a dissolução da folha octaédrica removendo os átomos de $\mathrm{Al}, \mathrm{Fe}$ ou $\mathrm{Mg}$ (de acordo com as características do material). Ao final da reação tem-se um material com elevada porosidade e consequentemente área superficial, além de uma solução ácida rica em $\mathrm{Al}, \mathrm{Fe}, \mathrm{Ca}$ e $\mathrm{Mg}$.

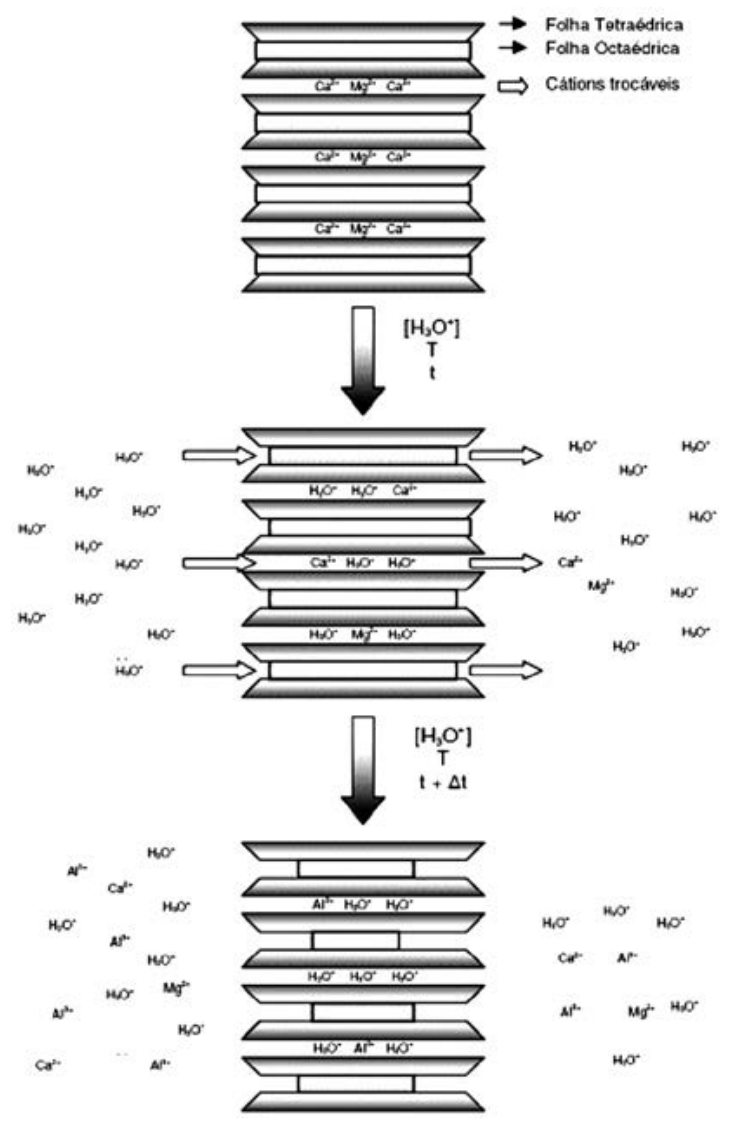

Figura 6: Modificações estruturais em argila ácido-ativada. [Figure 6: Structural changes in acid-activated clay.]

\section{Características superficiais das argilas ácido-ativadas}

\section{Área de superfície específica e porosidade}

A área de superfície específica, o volume, tamanho e distribuição de poros são parâmetros que afetam diretamente a capacidade de uma argila remover os pigmentos presentes em óleos vegetais. Esses parâmetros podem ser modificados mediante um tratamento com ácidos inorgânicos fortes. O aumento da área de superfície específica e volume dos poros incrementam a capacidade de adsorção de pigmentos pela argila [21].

Os efeitos da ativação de uma bentonita com ácido sulfúrico foram relatados [27]. Concluíram que o poder de clarificação aumenta com o incremento da área específica, acidez de superfície e porosidade, sendo que este último parâmetro apresentou-se como o mais importante.

Quanto mais finas forem as partículas de argila, maior será a área de superfície externa que a mesma apresentará e, portanto maior a capacidade de clarificação desta argila [21]. Como consequência, a taxa de filtração e a retenção de óleo na argila poderão ser negativamente afetadas (baixa taxa de filtração e alta retenção de óleo). Por isso, é necessário um controle rigoroso da distribuição granulométrica da argila ativada para que se tenham partículas suficientemente finas (para que apresentem eficiência adequada na remoção de pigmentos) e com taxa de filtração adequada (com reduzido nível de partículas ultrafinas).

A capacidade de adsorção de um determinado tipo de argila depende da acessibilidade das moléculas dos pigmentos nos poros da mesma. Consequentemente, o tamanho dos poros da argila é de fundamental importância para que ocorra a remoção dos pigmentos [28]. Os poros são classificados em microporos (menores que $2 \mathrm{~nm}$ ), mesoporos (entre 2 e $50 \mathrm{~nm}$ ) e macroporos (superiores a 50 nm) [29]. Os macroporos (localizados entre partículas) têm participação insignificante nos processos de adsorção quando comparados aos microporos e mesoporos (localizados dentro das partículas) [28].

\section{Sítios ativos de interação presentes nas argilas}

A superfície menos reativa encontrada em uma argila sob condições normais é a superfície neutra de siloxano. Ocorre em filossilicatos 2:1 que não sofreram substituição isomórfica e na face do Si tetraedral do grupo dos caulins. Os átomos de oxigênio da superfície do siloxano são bases fracas de Lewis (doador de um par de elétrons) e não são capazes de interagir com a água [30-32].

A folha tetraédrica e a folha octaédrica frequentemente têm seus átomos substituídos por átomos de menos valência nos minerais do tipo 2:1. Esse fenômeno é denominado de substituições isomórficas e resulta em uma carga resultante negativa no cristal [33]. As substituições isomórficas promovem a geração dos mais importantes sítios ativos presentes nas superfícies de uma argila [27].

Substituições isomórficas na folha octaédrica geram uma deficiência de carga deslocalizada (distribuída por 10 átomos de oxigênio basal), enquanto as substituições isomórficas na folha tetraédrica geram uma deficiência de carga mais localizada (distribuída por 3 átomos de oxigênio basal) [34]. Foi reportado que quando ocorrem substituições isomórficas na folha octaedral o caráter de base de Lewis da superfície de siloxano é reforçado [35].

O excesso de carga negativa é distribuído por todos os átomos de oxigênio da superfície, tornando a superfície da argila altamente ácida. Quanto à adsorção de espécies polares e orgânicas eletricamente carregadas, a localização (folha tetraédrica ou octaédrica) das substituiçõos isomórficas nos minerais 2:1 terá grande influência [36].

Para compensar a carga negativa gerada pelas substituições isomórficas, são adsorvidos nas faces do cristal de argila cátions compensadores de carga. Quanto menor o raio 
e maior a carga do cátion adsorvido, maior será a capacidade do cátion gerar sítios de Brönsted após sua hidratação. Nas bordas dos cristais podem existir cátions gerados por ligações quebradas. Esses cátions também sítios de Brönsted após a hidratação. As moléculas de água polarizada em torno dos cátions trocáveis e dos átomos não coordenados podem doar prótons mais facilmente para solutos orgânicos [37]. Cátions trocáveis e átomos não coordenados sem hidratação apresentam-se como sítios ácidos de Lewis [38]. A acidez de Lewis nas argilas é atribuída a átomos de $\mathrm{Al}^{3+}, \mathrm{Fe}^{3+} \mathrm{e}$ $\mathrm{Mg}^{2+}$ presentes nas bordas quebradas dos cristais. Embora a superfície das bordas represente apenas $10 \%$ da superfície total do cristal, é suficiente para proporcionar significativas propriedades ácidas as argilas [39, 40].

Outro tipo de sítio ativo presente em argilas está relacionado à presença de grupos hidroxila $\mathrm{Si}-\mathrm{OH}, \mathrm{Al}-\mathrm{OH} \mathrm{e}$ $\mathrm{Mg}-\mathrm{OH}$ na superfície. Esses grupos, quando expostos a um pH baixo, são protonados, funcionando como sítios ácidos de Brönsted [36].

\section{PROCESSO DE REMOÇÃO DE PIGMENTOS}

$\mathrm{Na}$ indústria, a etapa de remoção de pigmentos com o emprego de materiais adsorventes pode ser denominado de processo de branqueamento, descoramento ou clarificação. Independente da denominação atribuída, esse processo apresenta-se como uma das etapas do refino de óleos vegetais.

O processo de branqueamento é realizado após a degomagem e desacidificação do óleo vegetal, sob vácuo, com temperatura de contato tipicamente na faixa de 80 a 120 ${ }^{\circ} \mathrm{C}$ e com tempo de contato variando entre 20 e $40 \mathrm{~min}$. A dosagem da argila é variável, dependendo tanto do processo quanto do óleo. Em óleos vegetais, pode variar entre $0,25 \%$ e $2 \%$ [21].
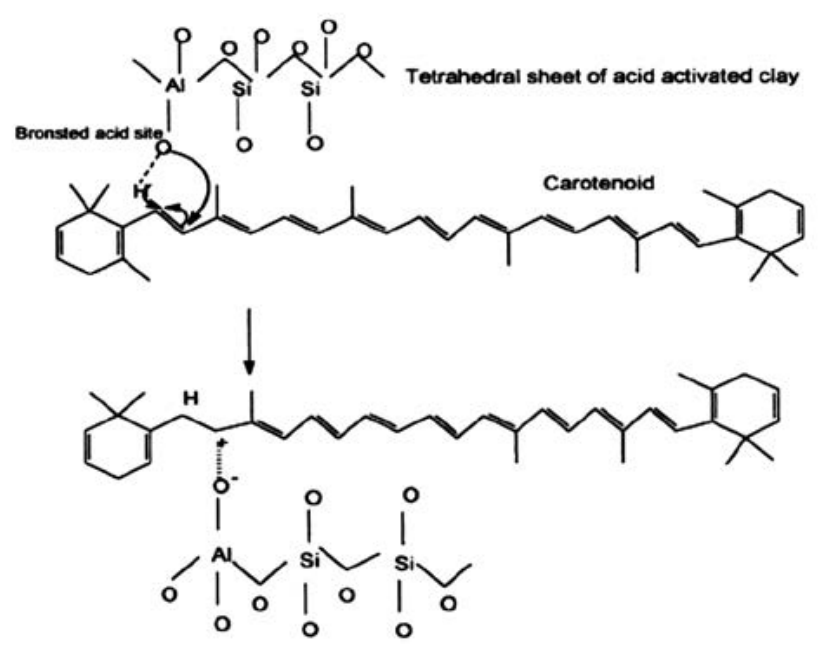

Figura 7: Mecanismo de adsorção do betacaroteno nos sítios de Brönsted [16].

[Figure 7: Mechanism of adsorption of carotene in Brönsted sites [16].]

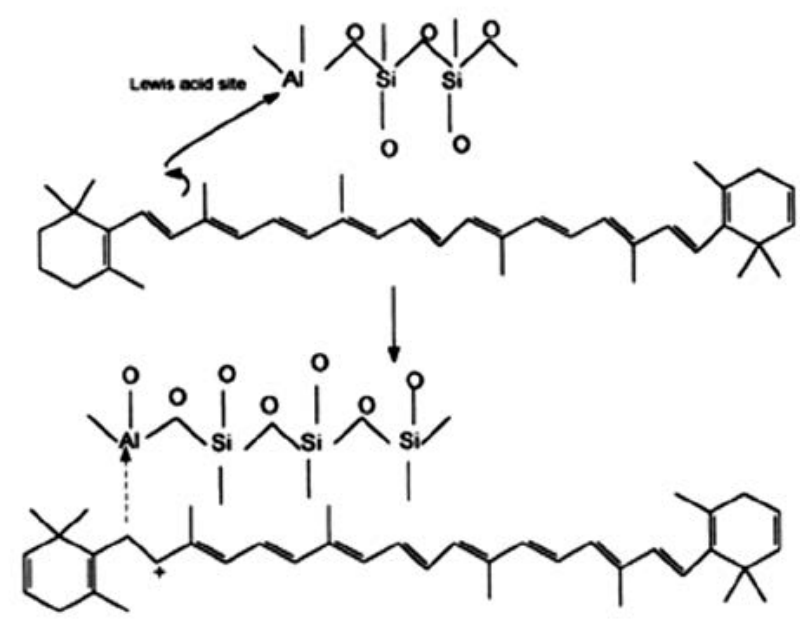

Figura 8: Mecanismo de adsorção do betacaroteno nos sítios de Lewis [16].

[Figure 8: Adsorption mechanism of beta-carotene in Lewis sites [16].]

Considerando que os pigmentos presentes nos óleos vegetais são clorofila e betacaroteno, alguns autores propuseram mecanismos de interação entre a superfície das argilas ácido-ativadas e as moléculas dos pigmentos.

A molécula de betacaroteno ataca a superfície da argila na forma de um íon de carbono, formando ligações coordenadas com os sítios de Lewis (Fig. 7) ou formando ligação de hidrogênio com os sítios de Brönsted (Fig. 8) presentes na argila ativada [41].

Os aspectos termodinâmicos da adsorção de moléculas de betacaroteno na superfície da sílica gel e do adsorvente comercial floristil foram verificados [42]. $\mathrm{O}$ valor de $\Delta \mathrm{H}$ positivo indicou que a adsorção é um processo de natureza endotérmica. Foi verificado ainda que o valor negativo de $\Delta \mathrm{G}$ indica que a adsorção de betacaroteno é um processo espontâneo para os adsorventes utilizados [42].

Foi observado que há dependência da acidez de Brönsted na capacidade de adsorção de clorofila na argila ativada [43]. Foram propostos dois mecanismos para este fenômeno, que podem ocorrer separados ou em combinação: A transferência de um próton (ou prótons) a partir da superfície da argila para a molécula de clorofila presente no óleo vegetal torna a molécula eletricamente carregada com uma carga líquida positiva. Essa característica faz com que a mesma seja presa a superfície negativa da argila por forças eletrostáticas. Quanto maior o número de prótons maior o número de moléculas de clorofila que poderão ser protonadas antes da adsorção; adsorção de moléculas de clorofila não protonadas por sítios ácidos da superfície nos sitos de Brönsted no interior dos poros da argila. Para que haja a difusão das moléculas para o interior da argila é necessário volume e tamanho de poros adequados.

Foi concluído que a adsorção de clorofila em argilas ácido-ativadas é dependente da acidez de Brönsted presente nas argila [43]. Analisando a argila ácido-ativada carregada com moléculas de clorofila adsorvidas, observou-se que os sítios de Brönsted são aqueles que interagem com a 
clorofila. Pelo fato de que as moléculas são protonadas e em seguidas adsorvidas por forças eletrostáticas, a carga negativa superficial da argila é muito importante.

Foi proposto que há a protonação de moléculas de clorofila por grupos hidroxila $\mathrm{Si}-\mathrm{OH}$ protonados, formado sítios de Brönsted do tipo $\mathrm{Si}_{-} \mathrm{OH}_{2}^{+}$(Fig. 9) [44]. As moléculas de clorofila protonadas são adsorvidas por forças eletrostáticas na superfície da argila carregada negativamente.

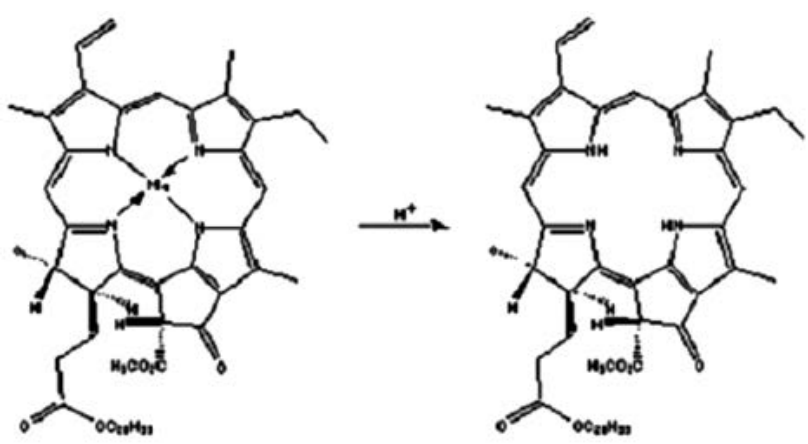

Figura 9: Protonação da molécula de clorofila [44].

[Figure 9: Protonation of the chlorophyll molecule [44].]

\section{CONSIDERAÇÕES FINAIS}

As características necessárias para que uma argila de clarificação tenha um bom desempenho na indústria são as altas capacidades de remoção de pigmentos, altas taxas de filtração e baixa retenção de óleo. Em uma argila descorante, a capacidade de adsorção de pigmentos dependerá da natureza da estrutura cristalina que compõe a argila antes da ativação. Argilas puras (baixo nível de contaminação por quartzo, feldspato, carbonatos, entre outros) com estrutura cristalina do tipo 2:1 e com alto grau de substituição isomórfica sugerem a obtenção após a ativação ácida de argilas descorantes eficientes. Após o tratamento ácido, argilas do tipo 2:1 e com alto grau de substituição isomórfica apresentam elevada área superficial específica; volume, distribuição e tamanho de poros que favorecem a adsorção; sítios de Lewis e Brönsted distribuídos pelas superfícies dos cristais de argila e responsáveis pela remoção das moléculas de clorofila e betacaroteno. Essas características são obtidas controlando a temperatura, o tempo e a concentração de ácido durante o processo de ativação. Para cada tipo de argila haverá uma condição ideal para estes parâmetros. Para a obtenção de altas taxas de filtração e baixa retenção e óleo na argila descorante, é necessário que haja um controle rigoroso na distribuição granulométrica da argila descorante (diâmetro médio das partículas entre 25 e $30 \mu \mathrm{m}$ e com fração inferior a $5 \%$ de partículas com diâmetros menores que $5 \mu \mathrm{m})$.

\section{REFERÊNCIAS}

[1] P. Souza Santos, “Ciência e Tecnologia de Argilas”, Vol. 1, Edgar Blücher, S. Paulo, SP (1975) 340.

[2] P. Souza Santos, "Ciência e Tecnologia de Argilas", Vol.

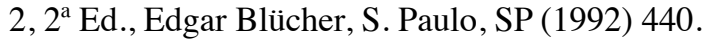

[3] P. Souza Santos, "Ciência e Tecnologia de Argilas", Vol. 3, $2^{\text {a }}$ Ed., Edgar Blücher, S. Paulo, SP (1992) 234.

[4] A. C. V. Coelho, P. Souza Santos, H. S. Santos, Química Nova 30, 5 (2007) 1282.

[5] O. S. Baraúna, Processo de Adsorção de Pigmentos de Óleo Vegetal com Argilas Esmectíticas Ácido-Ativadas, Tese Dr., Engenharia Química, Unicamp, Campinas, SP (2006) 173.

[6] J. H. Von Elbe, "Colorantes", in: O. W. Fennema, "Química de los Alimentos", $2^{\mathrm{a}}$ Ed., Wisconsin-Madison, Zaragoza (2000) 782.

[7] M. G. Ferri, "Fisiologia Vegetal", $2^{\text {a }}$ Ed., Edusp, S. Paulo, SP (1979) 350.

[8] F. O. Bobbio, P. A. Bobbio, "Introdução à Química dos Alimentos", Varela, S. Paulo, SP (1989) 25.

[9] H. B. W. Patterson, "Bleaching and Purifying Fats and Oils: Theory and Practice”, $2^{\text {nd }}$ Ed., American Oil Chemists' Society, Urbana, EUA (1992) 242.

[10] NBR 6502: "Rochas e Solos", Associação Brasileira de Normas Técnicas, Rio de Janeiro, RJ (1995).

[11] R. C. Mackenzie, Clay Minerals Bull. 4 (1959) 52.

[12] A. R. V. Silva, H. C. Ferreira, Rev. Eletr. Mater. Proc. 3, 2 (2008) 26.

[13] H. H. Murray, "Applied Clay Mineralogy", Elsevier, Amsterdam, Holanda (2007) 100.

[14] S. Kaufhold, R. Dohrmann, Clay Minerals 45 (2010) 441

[15] J. V. F. L. Cavalcanti, M. Da Motta, C. A. M. Abreu, O. S. Baraúna, L. A. P. Portela, Cerâmica 56, 338 (2010) 168. [16] E. Srasra, M. Trabelsi-Ayedi, Appl. Clay Sci. 17 (2000) 71.

[17] S. Balci, Clay Minerals 34, 4 (1999) 647.

[18] M. Myriam, M. Suárez, J. M. Martin-Pozas, Clays Clay Minerals 46, 3 (1998) 225.

[19] K. Emmerich, A. Steudel, R. Schuhmann, P. G. Weidler, F. Ruf, U. Sohling, Clay Minerals 45 (2010) 477.

[20] J. E. A. Piluski， D. Hotza, Química Nova 31 (2008) 1165.

[21] F. R. Valenzuela Díaz, P. Souza Santos, Química Nova 24, 3 (2001) 345.

[22] D. Woumfo, R. Kamga, F. Figueras, D. Njopwouo, Appl. Clay Sci. 37 (2007) 149.

[23] E, Teixeira-Neto, A. A. Teixeira-Neto, Química Nova 32, 3 (2009) 809.

[24] F. Hussin, M. K. Aroua, W. M. A. Wan Daud, Chem. Eng. J. 170 (2011) 90.

[25] J. Madejová, J. Bujdák, M. Janek, P. Komadel, Spectrochim. Acta Part A: Molecular Biomolecular Spectroscopy 54 (1998) 1397.

[26] H. He, J. Guo, X. Xie, H. Lin, L. Li, Clay Minerals 37 (2002) 337.

[27] H. Noyan, M. Önal, Y. Sarikaya, Food Chem. 105 (2007) 156

[28] H. Babaki, A. Salem, A. Jafarizad, Mater. Chem. Phys. 108, 2-3 (2008) 263.

[29] S. J. Gregg, K. S. W. Sing, “Adsorption, Surface Area 
and Porosity", $2^{\text {nd }}$ Ed., Academic Press, Londres, UK (1982).

[30] R. F. Giese, C. J. Van Oss, Rev. Mineralogy Geochem. 28 (1993) 327.

[31] L. J. Michot, F. Villieras, M. Francois, J. Yvon, R. Ledred, J. M. Cases, Langmuir 10 (1994) 3765.

[32] C. Charnay, S. Lagerge, S. Partyka, J. Colloid Interface Sci. 233 (2001) 250.

[33] R. W. Grimshaw, "Chemistry and Physics of Clays", $4^{\text {th }}$ Ed., Techbooks, Virginia, EUA (1971).

[34] C. T. Johnston, "Sorption of Organic Compounds on Clay Minerals", in: B. Sawhney, (Ed.). "Organic Pollutants in the Environment", Clay Minerals Soc. Boulder, EUA (1996) 44.

[35] G. Sposito, N. T. Skipper, R. Sutton, S. H. Park, A. K. Soper, J. A. Greathouse, Proc. Natl. Acad. Sci. United States of America, 96, 7 (1999) 3358.

[36] R. A. Schoonheydt, C. T. Johnston, "Surface and Interface Chemistry of Clay Minerals", in: F. Bergaya, B. K.
G. Theng, G. Lagaly (Eds.), "Handbook of Clay Science", Oxford, UK (2006) 87.

[37] C. E. Fernandes, Argilas Modificadas como Catalisadores Ácidos Sólidos, Tese Dr. Química, Univ. da Madeira, Madeira, Portugal (2007) 254.

[38] E. L. Moreno, K. Rajagopal, Química Nova 32, 2 (2009) 538.

[39] B. K. G. Theng, "The Chemistry of Clay-Organic Reactions", Wiley, Hoboken (1974) 343.

[40] J. F. Lambert, G. Poncelet, Topics in Catalysis 4 (1997) 43.

[41] N. Sarier, C. Güler, J. Am. Oil Chem. Soc. 66, 7 (1989) 917.

[42] A. L. Ahmad, S. R. Chan, S. R. Abd Shukor, M. D. Mashitah, Chem. Eng. J. 148 (2009) 378.

[43] R. Mokaya, W. Jones, M. E. Davies, M. E. Whittle, J. Solid State Chem. 111 (1994) 157.

[44] E. Sabah, J. Colloid Interface Sci. 310 (2007) 1.

(Rec. 31/03/2013, Ac. 15/11/2013) 